\title{
O demônio de Carnap
}

Lorenzo Baravalle

\section{Constructing the world}

David J. Chalmers

Oxford University Press

Oxford, 2012, 494 págs.

Não é fácil apresentar o último livro de David Chalmers para seu potencial leitor, já que nele, na verdade, escondem-se muitos livros, muitos caminhos alternativos de leitura e, acima de tudo, muitos estímulos para diferentes reflexões filosóficas. De acordo com as intenções do autor, Constructing the world é um texto de "epistemologia metafísica (ou deveria ser metafísica epistemológica?): grosso modo, epistemologia a serviço de uma imagem global do mundo e de nossa concepção deste" (Chalmers, 2012, p. xx).

Pode-se ver o presente livro como procurando realizar uma versão do projeto de Carnap no Aufbau: aproximadamente, construir um plano (blueprint) do mundo ou, ao menos, construir um plano para um plano, providenciando um vocabulário no qual tal plano pode ser dado (p. xviII).

Ao longo dos oito capítulos que compõem o livro e dos numerosos excursus, que ampliam o alcance da argumentação principal para a elucidação das mais diversas problemáticas conceituais, Chalmers trata temas que vão desde a metafísica da modalidade até a filosofia da mente, desde a semântica até a filosofia da ciência, e desde a interpretação do empirismo lógico até a epistemologia formal. Dada a vastidão e a profundidade do texto, e tendo em conta que o próprio autor ( $\mathrm{p}$. xxv-xxvi) reconhece a importância de privilegiar um caminho de leitura por vez, eu seguirei aqui aquilo que, provavelmente, mais pode interessar ao leitor de Scientiae Studia, isto é, o caminho que, partindo de uma original recolocação do problema do conhecimento e passando por uma reconsideração do legado de Carnap, conduz a uma reflexão sobre a unidade das ciências e a estrutura do mundo. Paralelamente, prestarei atenção às qualidades que a análise de Chalmers possui como ferramenta metateórica. 


\section{Carnap encontra Laplace}

O titulo do livro de Chalmers é uma clara referência, e homenagem, ao Estrutura lógica do mundo (Aufbau) de Rudolf Carnap (cf. 1967 [1928]). Porém, Carnap não é seu único "herói”. Já nas primeiras páginas, o autor introduz a noção central de toda a obra, a saber, a de escrutabilidade, inspirada em Pierre-Simon Laplace. ${ }^{\mathbf{1}}$ Este último autor, em seu célebre tratado sobre probabilidade, apresenta a conhecida imagem de um intelecto - comumente chamado de "demônio de Laplace" - capaz de determinar, a partir de um certo número de informações sobre a realidade física e potência de raciocínio suficiente, a verdade de qualquer acontecimento passado, presente ou futuro (Laplace, 2010 [1814], p. 42-3). Para o demônio de Laplace, diz Chalmers, "todas as verdades sobre o mundo são escrutáveis a partir de algumas verdades básicas” (p. XIII). A noção de escrutabilidade pode ser entendida, em uma primeira aproximação, como a ideia de que "o mundo é em certo sentido compreensível, ao menos dada uma certa classe de verdades básicas sobre o mundo" ( $\mathrm{p}$. XIII). Obviamente, a escolha dessa classe de verdades é tudo menos trivial e, a esse propósito, é geralmente aceito que ela é, em Laplace, tendenciosa, já que pressupõe o determinismo, ou ao menos incompleta, dado que o demônio não tem acesso a verdades fenomênicas, matemáticas ou morais, entre outras.

Chalmers (p. xIv, ss; cap. l) defende que a noção de escrutabilidade, independentemente dos problemas relacionados com a perspectiva laplaceana, possui um grande valor filosófico. Essa noção denota, muito em geral, uma relação entre a classe de verdades básicas e qualquer outra proposição verdadeira $p$. Ela foi, ao longo da tradição empirista e, em particular, por Carnap, considerada como uma relação de definibilidade entre conceitos. No Aufbau, a definibilidade é, mais especificamente, associada com a possibilidade de construir - isto é, de mostrar a estrutura lógica de - os conceitos mais complexos (das ciências, por exemplo) a partir de uma relação simples e primitiva, a saber, a da similaridade fenomênica entre as experiências. Ao resgatar a inspiração construcionista carnapiana, Chalmers alinha-se - mais ou menos explicitamente àqueles autores que, como Richardson (1998) ou Friedman (1999), rejeitam a interpretação clássica do Aufbau em termos fundacionalistas e fenomenalistas (cf. Ayer, 1946; Quine, 1951). A escolha da base fenomênica, entendida como coleção de dados dos sentidos (sense-data), para a construção dos conceitos mais complexos, não é essencial na realização do projeto carnapiano. Carnap mesmo, além de admitir explicitamente a possibilidade de partir de outro tipo de base, fisicalista (Carnap, 1967 [1928], $\S 59$ ), para realizar a mesma tarefa, acaba tentando construir a estrutura conceitual do

1 Há, ainda, um terceiro "herói” no livro de Chalmers, Frege, do qual o autor pretende resgatar, por meio de certas aplicações da noção de escrutabilidade, a teoria do significado e a distinção entre sentido e referência. 
mundo inteira a partir de uma base puramente lógica $\left(\$ 15^{3-5}\right)$; desfazendo-se, portanto, dos pressupostos fenomenalistas.

Essa flexibilidade na hora de escolher os elementos básicos da construção, porém, não ajuda Carnap frente a outro tipo de crítica. O problema principal do Aufbau, de acordo com Chalmers, é a identificação da escrutabilidade com uma relação de definibilidade puramente extensional. A maioria dos conceitos - ou, em outros termos, a maioria das verdades não básicas - não podem ser reduzidas a outros conceitos (ou verdades) mais básicos de maneira que estes últimos constituam suas condições necessárias e suficientes (cf. Wittgenstein, 1953; Kripke, 1980). Prova disso é que, para quase qualquer definição, é possível encontrar contraexemplos. Carnap, mais uma vez, reconhece esse problema, e tenta resolvê-lo por meio de critérios intencionais (cf. Carnap, 1947; 1955), vale dizer, regras semânticas que identificam apenas contextualmente o valor de verdade de uma determinada expressão. Inspirando-se nessa solução, Chalmers (p. 12-9) nega que a relação de escrutabilidade seja propriamente definicional. Para que sentenças não básicas sejam escrutáveis a partir de sentenças básicas, não é necessário que sejam disponíveis definições extensionais - as quais, quando presentes, são fundadas na relação de escrutabilidade, e não vice-versa-, mas apenas intenções, as quais permitem, por si só, determinar seu valor de verdade com suficiente exatidão, dado um certo cenário epistêmico (p. 204-11; excurso 10). Por exemplo, embora não possuamos nenhuma definição extensional do conceito de "conhecimento" que seja totalmente imune aos contraexemplos de tipo Gettier, ela não parece necessária para que possamos reconhecer que, de fato, os contraexemplos de tipo Gettier não constituem conhecimento: é suficiente uma "definição aproximada" e implícita (cf. p. 204-11;381-5) do conceito.

Ora, embora Chalmers admita vários tipos de escrutabilidade não definicional, ${ }^{2}$ para os presentes fins, é suficiente que nos concentremos naquilo que ele considera o mais importante: a escrutabilidade a priori. A noção de escrutabilidade configura-se, nessa interpretação, como uma relação entre uma classe ou "família" (p. 20) de sentenças $C$, uma sentença $S$ e um sujeito $s$ tal que "S é escrutável a priori desde $C$ por $s$ se e somente se $s$ está na posição de conhecer a priori que se $C$, então $S$ " (p. 4.0). A partir dessa relação, Chalmers enuncia a seguinte tese.

2 Estes, além de constituírem-se a partir de bases distintas, podem ser, principalmente, inferenciais ou condicionais. A distinção remete às modalidades de conhecimento próprias de, respectivamente, um demônio laplaceano real ou meramente possível. Com o fim de evitar uma série de consequências paradoxais - in primis, o paradoxo de Fitch sobre a cognoscibilidade (cf. Fitch, 1963; Chalmers, 2012, p. 29 ss.) -, Chalmers expressa uma clara preferência para o segundo tipo de escrutabilidade, mas não precisamos aqui entrar nos detalhes. Para isso, ver Chalmers (2012, cap. 2). 
Escrutabilidade a priori: existe uma classe compacta de verdades tal que para qualquer proposição $p$, um intelecto laplaceano estaria na posição de saber a priori que, se as verdades contidas nessa classe são o caso, então $p$ (p. xvi). ${ }^{3}$

O termo "compacto" define um atributo da classe de verdades básicas, que deve conter sentenças limitadas e evitar trivializações, tais como uma "supersentença" matemática que inclui todos os estados do mundo (cf. p. 20 ss.). 4 A característica fundamental da tese é que ela se compromete com a existência de uma base compacta que é suficiente para que um hipotético sujeito (a) tenha acesso a ela, (b) seja capaz de certa potência de raciocínio e (c) possa comprovar que as verdades empíricas contidas nela refletem estados de coisas de nosso mundo ou de algum outro mundo possível, possa escrutar, a priori (isto é, sem precisar recorrer ulteriormente à experiência) a verdade de qualquer sentença. Dessa maneira, o problema de identificar tal base volta a ser central e, para reduzir a complexidade desse problema, Chalmers recorre, nos terceiro e quarto capítulos, a uma idealização análoga ao demônio de Laplace, a saber, o que denomina "cosmocópio".

\section{O PROBLEMA DA BASE: AVENTURAS COM O COSMOCÓPIO}

Já no primeiro capítulo, Chalmers introduz ao que, para ele, deveria ser a base a partir da qual "todas as verdades macroscópicas ordinárias são implicadas a priori”. 5 Embora, como veremos, seja admitida certa liberdade com respeito à escolha das famílias de sentenças que a compõem, para Chalmers, ela é um conjunto de verdades da física (tanto macroscópicas quanto microscópicas), verdades fenomênicas (referentes a qualia), verdades indexicais (“eu-sou-de-tal-e-tal-maneira”, "agora-é-de-tal-e-tal-manei-

3 Chalmers distingue, no texto, "escrutabilidade" (com caixa baixa), para se referir a uma relação de escrutabilidade, de "Escrutabilidade" (com caixa alta), para introduzir uma tese sobre escrutabilidade (p. 39).

${ }_{4}$ Note-se certa ambivalência, por parte de Chalmers, na caracterização das verdades como "sentenças" ou "proposições" verdadeiras, na apresentação de diferentes relações ou teses de escrutabilidade. Em geral, eu não diferenciarei aqui entre os dois termos, mas empregarei de preferência "sentenças", conforme as recomendações de Chalmers (cf. p. 42-7; excurso 3).

5 São excluídas, das “verdades macroscópicas ordinárias”, as verdades sobre a matemática, a moralidade, a ontologia, a intencionalidade, a modalidade e algumas outras, as quais são tratadas como casos especiais no sexto capítulo. Não apresentarei o conteúdo desse capítulo no corpo da resenha, mas vale a pena precisar duas questões. A primeira, terminológica, é que o atributo "macroscópico", com relação às verdades escrutáveis, não se opõe necessariamente a “microscópico". Verdades relacionadas com a estrutura da matéria, por exemplo, são escrutáveis. Apenas algumas verdades no domínio quântico são excluídas pelas verdades macroscópicas ordinárias e representam casos especiais. Em segundo lugar, é importante ressaltar que inclusive essas verdades especiais são escrutáveis, uma vez que sejam aportados certos ajustes na base (discutidos nos sexto e sétimo capítulos). 
ra”) e uma sentença “isso-é-tudo", que certifica que não há nada mais (em um determinado mundo possível, ou cenário epistêmico) do que é expressado nas sentenças básicas ou nas sentenças escrutadas a partir delas (p. 111; excurso 5). Para fazer referência a tal base, Chalmers usa o acrônimo PQTI (physics, qualia, that's all, indexicals). Como antecipei há pouco, para justificar a escolha de PQTI, Chalmers recorre, nos terceiro e quarto capítulos, a uma idealização, o cosmocópio, que se revela muito útil na hora de compreender melhor os problemas filosóficos em jogo e, a meu ver, também como instrumento analítico em geral.

O cosmocópio é um dispositivo imaginário - mas epistemicamente possível que permite a um determinado usuário, $s$, estabelecer o valor de verdade de qualquer sentença ordinária $M$. Ele

armazena todas as informações contidas em PQ[T]I e as torna utilizáveis. Em particular, ele contém (1) um supercomputador que armazena a informação e realiza todos os cálculos necessários; (2) ferramentas que usam $P$ para ampliar uma região qualquer do mundo e para fornecer informações sobre a distribuição da matéria nessas regiões; (3) um dispositivo de realidade virtual que produz conhecimento direto de qualquer estado fenomênico descrito em $Q$; (4) um marcador "tu estás aqui" que carrega a informação contida em I; e (5) dispositivos de simulação que proporcionam informações sobre contrafáticos, exibindo os estados físicos e fenomênicos que se produziriam sob as várias circunstâncias contrafactuais especificadas por PQ[T]I (p. 114).

Um exemplo ajudará a tornar mais claro o funcionamento do cosmocópio. Imagine-se que queira aferir o valor de verdade da seguinte sentença $M$ : "no dia 10 de outubro de 1820, às 11 horas, Napoleão Bonaparte estava observando uma garrafa de vinho na mesa da sala de sua residência na ilha de Santa Helena". Ao entrar no cosmocópio, terão acesso a todas as informações relevantes para identificar, sem possibilidade de erro, as características físicas da sala de Napoleão em Santa Helena em 1820. Em particular, poderão conferir que a composição molecular do líquido contido na garrafa na frente de Napoleão corresponde, efetivamente, a, digamos, um Châteauneufdu-Pape de 1812 e não a água colorida, ou a uma ficção produzida por um gênio maligno. Ao mesmo tempo, experimentarão as sensações de Napoleão naquele momento, podendo assim comprovar que ele estava realmente observando (e acreditando estar observando) essa garrafa e não, por exemplo, uma mosca voando na frente dele ou uma alucinação provocada pelo envenenamento por arsênico. Também poderão pedir para o cosmocópio mudar algumas das verdades básicas, de modo a aceder a um mundo possível no qual a garrafa na frente de Napoleão não contém vinho, mas água colorida, e 
comprovar, assim, se ele continuaria acreditando estar observando uma garrafa de vinho. Novos cenários epistêmicos podem ser obtidos simplesmente inserindo condicionais hipotéticos no cosmocópio, o qual se encarregará de produzir as modificações relevante em PQTI.

A função dessa idealização é mostrar como a base PQTI é suficiente para escrutar qualquer outra verdade, real ou meramente possível. Para isso, é importante notar que o cosmocópio não produz, propriamente, conhecimentos. Ele se limita a fornecer certas informações físicas e representações fenomênicas a partir de PQTI. É o usuário $s$ quem determina o valor de verdade de uma sentença $M$, à luz das evidências, completas, disponíveis no cosmocópio. Embora amplie impressionantemente os conhecimentos básicos de $s$ e proporcione uma capacidade de raciocínio praticamente ilimitada, o cosmocópio não é nada mais que uma "extensão" de $s$. Em outras palavras, não é o cosmocópio o demônio de Laplace, mas a união do usuário e do cosmocópio, a qual constitui, em última instância, o sujeito epistêmico ideal. Se aceitamos que o usuário no cosmocópio é efetivamente capaz de determinar o valor de verdade de qualquer sentença ordinária, então aceitamos, ipso facto, que PQTI é a base própria da relação de escrutabilidade. Para quem não estiver convencido, Chalmers mostra, em primeiro lugar - e contra possíveis objeções céticas -, que não é possível que PQTI seja verdadeiro e $M$ falso, que ele chama de "argumento da eliminação" (p. 120-5) e, em segundo lugar, que não há verdades ordinárias que fiquem fora do alcance do cosmocópio, que corresponde ao "argumento da cognoscibilidade" (cf. p. 125-34). Contudo, tudo isso não é suficiente para justificar a tese da escrutabilidade a priori. Para esse fim, Chalmers deve mostrar que, uma vez que $s$ entra no cosmocópio, ele aceita que PQTI $\rightarrow M$ é verdadeiro independentemente de qualquer experiência, isto é, confiando apenas na relação de escrutabilidade a partir de PQTI.

No quarto capítulo, Chalmers apresenta três argumentos definitivos para aceitar a tese da escrutabilidade a priori com base PQTI. O primeiro é o argumento da suspensão do juízo (p. 159-60). Se nos imaginamos, antes de entrar no cosmocópio, em um cenário cético análogo ao das Meditações metafísicas de Descartes, não é claro em que sentido a experiência jogaria um papel qualquer na aceitação de PQTI $\rightarrow$ M. Sendo que o cosmocópio, durante o processamento da informação, não é influenciado por nenhuma nova evidência empírica, resulta ao menos plausível que também o usuário que previamente suspendeu o juízo chegue a saber PQTI $\rightarrow M$ sem recorrer à experiência. O segundo argumento é o da antecipação (cf. p. 160-7). Poder-se-ia pensar que, até depois de uma suspensão do juízo, as evidências empíricas continuem jogando algum papel na posterior aceitação de verdades. Poder-se-ia, então, pensar que $s$, uma vez entrado no cosmocópio, não sabe realmente PQTI $\rightarrow M$, mas PQTI $\& E \rightarrow M$, onde $E$ é uma evidência empírica. Porém, Chalmers nota que, sendo PQTI suficiente para de- 
rivar $M, E$ deve necessariamente estar já incluído em PQTI e, portanto, PQTI $\& E \rightarrow M$ é escrutável a priori. Agora, se somamos todas as evidências empíricas $F$ e tentamos mostrar que elas jogam algum papel na aceitação de PQTI $\rightarrow M$, encontrar-nos-emos, analogamente, na situação em que PQTI \& $F \rightarrow M$ é escrutável $a$ priori. Finalmente, com o argumento que poderíamos chamar de "o papel justificativo" (cf. p. 167-9), Chalmers mostra que qualquer referência à experiência durante o uso do cosmocópio (pensem no nosso exemplo acerca de nossas percepções "napoleônicas") não joga realmente um papel justificativo em PQTI $\rightarrow M$, mas apenas causal ou de intermediação.

\section{A UNIDADE DA GIÊNGIA E A ESTRUTURA Do MUNDO}

Mas afinal quais são exatamente as sentenças que compõem PQTI? Em realidade, mais do que uma base determinada, ele representa, para Chalmers, um ponto de partida para definir, em claro espírito carnapiano, classes de verdades básicas mais fundamentais, isto é, subconjuntos mínimos dotados de alguma prioridade conceitual (cf. cap. 6-7), as quais, por sua vez, permitem formular novas versões de escrutabilidade (cf. cap. 8) - todas rigorosamente a priori -, com as mais diversas finalidades filosóficas. Diferentes bases mínimas servem para defender teses epistemológicas, semânticas ou metafísicas distintas, e é justamente nisso que reside a versatilidade da proposta de Chalmers. Embora, ao longo do livro, o autor expresse suas opiniões pessoais com respeito a várias temáticas, a tese da escrutabilidade a priori é, principalmente, um instrumento metafilosófico que pode ser empregado por pensadores das mais díspares tendências. Para dar um exemplo disso, apresentarei, na última parte desta resenha, a relação entre a escolha de bases restritas e a estrutura científica do mundo, a partir do que, para Chalmers, é uma consequência necessária da tese da escrutabilidade a priori, a saber, a unidade da ciência (cf. excurso 10).

A conexão entre a tese da escrutabilidade a priori e a unidade da ciência é bastante evidente quando pensamos que, conforme a primeira, todas as verdades e, portanto, todas as verdades científicas são escrutáveis a partir de uma certa base. Dado que, intuitivamente, as verdades científicas contidas em PQTI são principalmente verdades da física, resulta quase espontâneo considerar o reducionismo como uma consequência da tese da escrutabilidade a priori; o que é, de acordo com Chalmers (p. 3०2), admissível, mas deve ser tomado com cuidado. Como já vimos, a relação de escrutabilidade não é uma relação de definibilidade e, portanto, o reducionismo sugerido por ela é muito mais fraco que o reducionismo tradicional, fundado sobre critérios de significado dos empiristas lógicos (cf. Hempel, 1965, cap. 4). A escrutabilidade com base PQTI é compatível com o pluralismo e com diferentes enfoques metateóricos (p. 3०9). 
Por exemplo, ela não implica - embora tampouco exclua - o fisicalismo. O fisicalista é alguém que aceita, como verdades básicas, algo como PQTI (p. 290-8), isto é, uma versão de PQTI na qual as verdades contidas em $P$ são apenas verdades microfísicas ou, em um caso mais extremo, apenas PTI ou $P$, isto é, famílias de sentenças puramente físicas (para este último tipo de fisicalista, as qualidades (qualia) seriam totalmente escrutáveis a partir de estados físicos). Contudo, o fisicalismo não é a única (e, segundo Chalmers, nem a melhor) opção de "redução".

Os metafísicos discutem se o universo inteiro é mais fundamental do que as simples partes: os monistas sustentam que o todo funda as partes, enquanto os pluralistas sustentam que as partes fundam o todo. Analogamente, os fisicalistas sustentam que o físico é fundamental e funda o mental, enquanto os idealistas sustentam que o mental é fundamental e funda o físico, e os dualistas sustentam que tanto o físico quanto o mental são fundamentais (...). PQTI não resolve essas questões: ele é compatível tanto com a perspectiva monista como com a pluralista, e com as perspectivas fisicalista e dualista e, talvez, com a idealista (p. 270).

Novamente, a inspiração é o próprio Aufbau carnapiano, o qual, além de oferecer bases alternativas (fenomênica, fisicalista ou lógica), mostra indiferença ou, melhor dito, "tolerância" com respeito a várias posições filosóficas (cf. Carnap, 1967 [1928], $\S 75$, §177-8; Friedman, 1999, p. 132 ss.). Para Chalmers, todos os conceitos candidatos para formar parte de PQTI podem constituir alternativamente, dependendo de como sejam interpretados, elementos básicos ou derivados da relação de escrutabilidade (exceto $T$ e $I$, os quais parecem formar necessariamente parte da base). Como demonstração disso, no sétimo capítulo, são explicitadas as principais opções na escolha da classe mínima de conceitos básicos. Com relação a $P$, por exemplo, é igualmente aceitável definir os conceitos microfísicos como básicos (fisicalismo) ou como escrutáveis, por "ramseyficação" de conceitos macrofísicos e observacionais (p. 319-21). Quanto a $Q$, podemos considerar as qualidades secundárias (como cores, sons etc.) como primitivas, ou escrutáveis de interações fenomênicas entre sujeitos e objetos (funcionalismo conceitual) (cf. p. 321-4). Há, depois, outros conceitos básicos de difícil classificação, cujo status epistemológico e metafísico é objeto de disputa. Os conceitos de espaço e tempo e todas as expressões nômicas, por exemplo, podem ser considerados primitivos com respeito às entidades físicas e aos estados fenomênicos, mas também escrutáveis, idealisticamente, de conceitos fenomênicos ou, alternativamente, de certas distribuições (micro ou macro) físicas (cf. p. 325-40). É possível ainda que as verdades mais básicas da física sejam escrutáveis, em realidade, de verdades metafísicas mais primitivas (quidditas) (cf. p. $347^{-} 5^{3}$ ). Tomando certas verdades metafísicas - 
como, por exemplo, a irredutibilidade dos estados psíquicos, isto é, o pampsiquismo, que é uma posição cara a Chalmers (cf. 1996, p. 293-3o1; 2012, p. 359-61) - como básicas, é possível redefinir inteiramente a ordem das outras verdades escrutadas.

Como consequência dessa liberalidade filosófica, no oitavo capítulo, várias combinações compactas de conceitos básicos são apresentadas explicitando a estrutura do mundo, a qual é, a partir delas, escrutável (p. 4,06-22). Assim, caracterizar a base como uma classe de sentenças sobre coordenadas espaço-temporais conduz a conceber o mundo como uma estrutura quase matemática; escolher regularidades nômicas implica caracterizar a estrutura do mundo como fundamentalmente legiforme; uma base fenomênica pode definir uma estrutura análoga à do Aufbau ou, se nela são introduzidas certas verdade metafísicas, pampsiquista; finalmente, se a base é metafísica, a estrutura resultante será caracterizada pelas propriedades das quidditas aceitas. Bases híbridas e estruturas intermédias podem satisfazer outras sensibilidades metateóricas. Trata-se, contudo, apenas de esboços, já que (além do fato de não ser esta lista exaustiva), em cada caso, haveria - como Chalmers mesmo reconhece - que dedicar muito mais detalhe ao vocabulário, à forma das verdades básicas e às modalidades de construção das outras verdades. Chalmers declara, no final de sua obra, que

\begin{abstract}
eu não escrevi nenhum desses Aufbaus aqui (...), [mas] na medida em que a tese da escrutabilidade a priori é verdadeira, algum desses Aufbaus será possível. Haverá um vocabulário básico limitado no qual expressar as verdades básicas. Outras verdades serão deriváveis a partir dessas, ou por inferência a priori ou por uma definição aproximada. A estrutura geral dependerá da visão filosófica de cada um sobre a fenomenologia, o espaço-tempo, as leis da natureza, a quidditas, a normatividade, a intencionalidade, a ontologia, e assim por diante. Os detalhes dependerão de questões empíricas sobre física, fenomenologia e outros domínios. Mas temos razão de crer que um Aufbau bem-sucedido existe, em algum lugar do espaço filosófico (p. 429-3o).
\end{abstract}

Estudar o livro de Chalmers, e empregar suas sofisticadas ferramentas analíticas, sem dúvida, aproxima-nos desse lugar.@

\title{
Lorenzo Baravalle
}

Centro de Ciências Naturais e Humanas, Universidade Federal do ABC, Brasil. lorenzo_baravalle@yahoo.it 


\section{REFERÊNGIAS BIBLIOGRÁFIGAS}

Ayer, A. Language, truth and logic. New York: Dover, 1946.

CARnap, R. Meaning and necessity: a study in semantics and modal logic. Chicago: University of Chicago Press, 1947 .

. Meaning and synonymy in natural languages. Philosophical Studies, 6, 3, p. 33-47, 1955.

The logical structure of the world. Oakland: University of California Press, 1967 [1928].

Chalmers, D. J. The conscious mind. Oxford: Oxford University Press, 1996.

Constructing the world. Oxford: Oxford University Press, 2012.

Fitch, F. B. A logical analysis of some value concepts. Journal of Symbolic Logic, 51, p. 135-42, 1963.

Friedman, M. Reconsidering logical positivism. Cambridge: Cambridge University Press, 1999.

Hempel, C. G. Aspects of scientific explanation and other essays in the philosophy of science. New York: The Free Press, 1965 .

Kripke, S. Naming and necessity. Cambridge: Harvard University Press, 1980.

LaPlace, P.-S. Ensaio filosófico sobre as probabilidades. Rio de Janeiro: Pontifícia Universidade Católica/ Rio, 2010 [1814].

Quine, W. van O. Two dogmas of empiricism. Philosophical Review, 6o, p. 20-43, $195^{1}$.

Richardson, A. Carnap's construction of the world: the Aufbau and the emergence of logical empiricism. Cambridge: Cambridge University Press, $199^{8}$.

Wittgenstein, L. Philosophical investigations. London: Macmillan, $195^{3}$. 